\title{
LIPOSSARCOMA MIXÓIDE DE MEDIASTINO: RELATO DE CASO E REVISÃO DA LITERATURA*
}

\author{
Dante L. Escuissato ${ }^{1}$, Guilherme P. Adam², Emerson L. Gasparetto ${ }^{2}$, Paulo R. Benites Filho ${ }^{3}$, \\ Linei A.B.D. Urban ${ }^{2}$, Daniele Sakamoto ${ }^{4}$, Edson Marchiori ${ }^{5}$
}

\begin{abstract}
Resumo As neoplasias mediastinais de origem mesenquimal são raras, representando menos de $6 \%$ dos casos. A maioria são lipossarcomas, apesar da aparência cística ser incomum. Os autores apresentam um caso de paciente feminina com 58 anos de idade, com queixa de dispnéia, com piora progressiva desde os 52 anos. Estridor laríngeo era auscultado durante o exame físico, e a tomografia computadorizada de tórax demonstrou uma lesão cística no mediastino posterior. 0 tumor foi ressecado e o estudo histológico definiu o diagnóstico de lipossarcoma mixóide.
\end{abstract}

Unitermos: Tomografia computadorizada; Tumores mediastinais; Lipossarcoma mixóide.

Abstract Myxoid liposarcoma of the mediastinum: a case report and review of the literature.

Mediastinal neoplasms of mesenchymal origin are rare, accounting for less than $6 \%$ of these tumors. Most of these tumors are liposarcomas, although cystic lesions are uncommon. The authors present a case of a 58-year-old woman with progressively worsening dyspnea since she was 52-years-old. Laryngeal stridor was auscultable and a chest CT scan showed a cystic lesion in the posterior mediastinum. The tumor was resected and the histological examination revealed myxoid liposarcoma.

Key words: Computed tomography scan imaging; Medistinal tumors: Myxoid liposarcoma.

\section{INTRODUÇÃO}

O lipossarcoma mixóide representa cerca de $50 \%$ dos tumores mesenquimais do mediastino. Ao contrário de outros lipossarcomas, a variedade mixóide acomete uma população mais jovem, com pico de incidência na sexta década de vida. Localiza-se preferencialmente nos membros inferiores ( $75 \%$ dos casos) e raramente no mediastino $^{(\mathbf{1})}$. A apresentação cística na tomografia computadorizada é ainda mais infreqüente ${ }^{(2)}$. Os autores apresentam o caso de uma paciente com massa no mediastino posterior, a qual tinha aspecto cís-

\footnotetext{
* Trabalho realizado na Disciplina de Radiologia Médica do Departamento de Clínica Médica e no Departamento de Patologia Médica da Universidade Federal do Paraná (UFPR), Curitiba, PR.

1. Professor Assistente da Disciplina de Radiologia Médica da UFPR.

2. Médicos Residentes do Serviço de Radiologia Médica e Diagnóstico por Imagem do Hospital de Clínicas da UFPR.

3. Acadêmico de Medicina da UFPR.

4. Médica Residente do Serviço de Anatomia Patológica do Hospital de Clínicas da UFPR.

5. Professor Titular de Radiologia da Universidade Federa Fluminense (UFF), Coordenador Adjunto do Curso de Pós-Graduação em Radiologia da Universidade Federal do Rio de Janeiro (UFRJ).

Endereço para correspondência: Dr. Dante L. Escuissato. Ser viço de Radiologia Médica, Hospital de Clínicas da UFPR. Avenida General Carneiro, 181. Curitiba, PR, 80060-900. E-mail: danteluiz@onda.com.br

Recebido para publicação em 8/3/2004. Aceito, após revisão, em 13/8/2004.
}

tico na tomografia computadorizada, e cujo diagnóstico histológico foi de lipossarcoma mixóide.

\section{RELATO DO CASO}

Paciente feminina, 58 anos de idade, referindo estridor laríngeo há seis meses, disfagia e massa localizada no pescoço.
A radiografia de tórax revelou massa no mediastino posterior, com deslocamento anterior da traquéia. $\mathrm{O}$ exame contrastado de esôfago demonstrou que a lesão deslocava o esôfago anterior e lateralmente ( $\mathrm{Fi}$ gura 1), não havendo evidência de invasão de estruturas mediastinais. A tomografia computadorizada mostrou lesão arredondada, bem definida, hipodensa, medindo
Figura 1. Exame de esôfago contrastado revela lesão expansiva localizada no mediastino posterior, deslocando o esôfago anterior e lateralmente. Não há evidência de invasão do esôfago pela lesão.

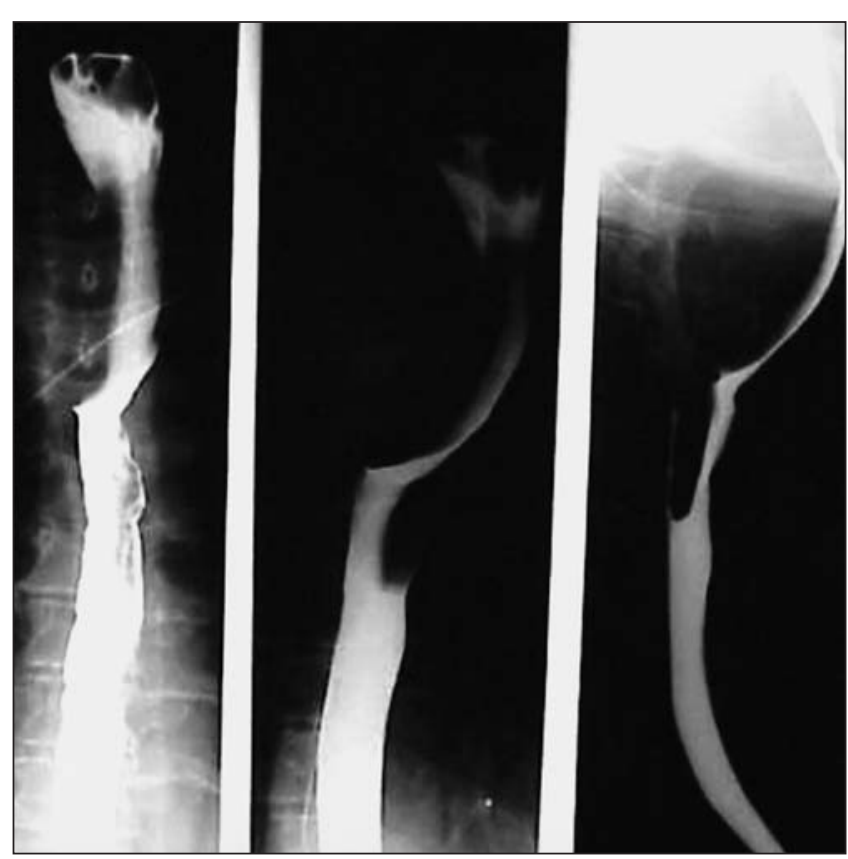



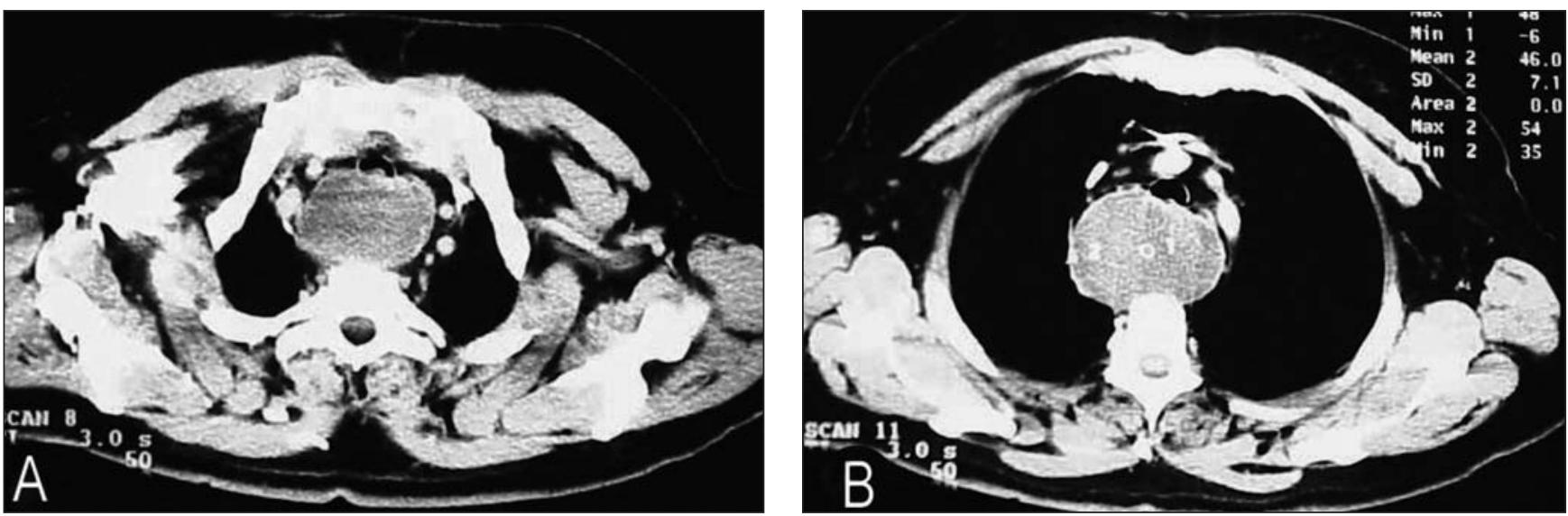

Figura 2. Tomografia computadorizada de tórax (janelas para mediastino) evidenciando lesão hipodensa, arredondada, bem definida, localizada no mediastino posterior. A lesão localiza-se à direita do esôfago e atrás da parede posterior da traquéia. A densidade no interior da lesão é de 21,9 unidades Hounsfield.

$6,5 \times 5,0 \mathrm{~cm}$, localizada posteriormente à traquéia e ao esôfago, deslocando estas estruturas anteriormente (Figura 2). Não houve alteração no padrão da imagem após a injeção de meio de contraste endovenoso. A densidade da lesão foi definida entre 21 e 26 unidades Hounsfield.

A paciente foi submetida a toracotomia direita, e a lesão, que não invadia estruturas adjacentes, foi removida totalmente. A lesão era cística, heterogênea, de $150 \mathrm{~g}$, com $9 \times 8 \mathrm{~cm}$ no seu maior eixo. A periferia do tumor era esbranquiçada e firme e em seu interior havia material gelatinoso amarronzado (Figura 3). Na microscopia foi encontrado estroma mixóide, com proliferação de células fusiformes e ovóides. Estas células formavam áreas de rosetas e, ao redor da lesão, havia uma pseudocápsula fibrótica (Figura 4). O diagnóstico histológico foi de lipossarcoma mixóide.

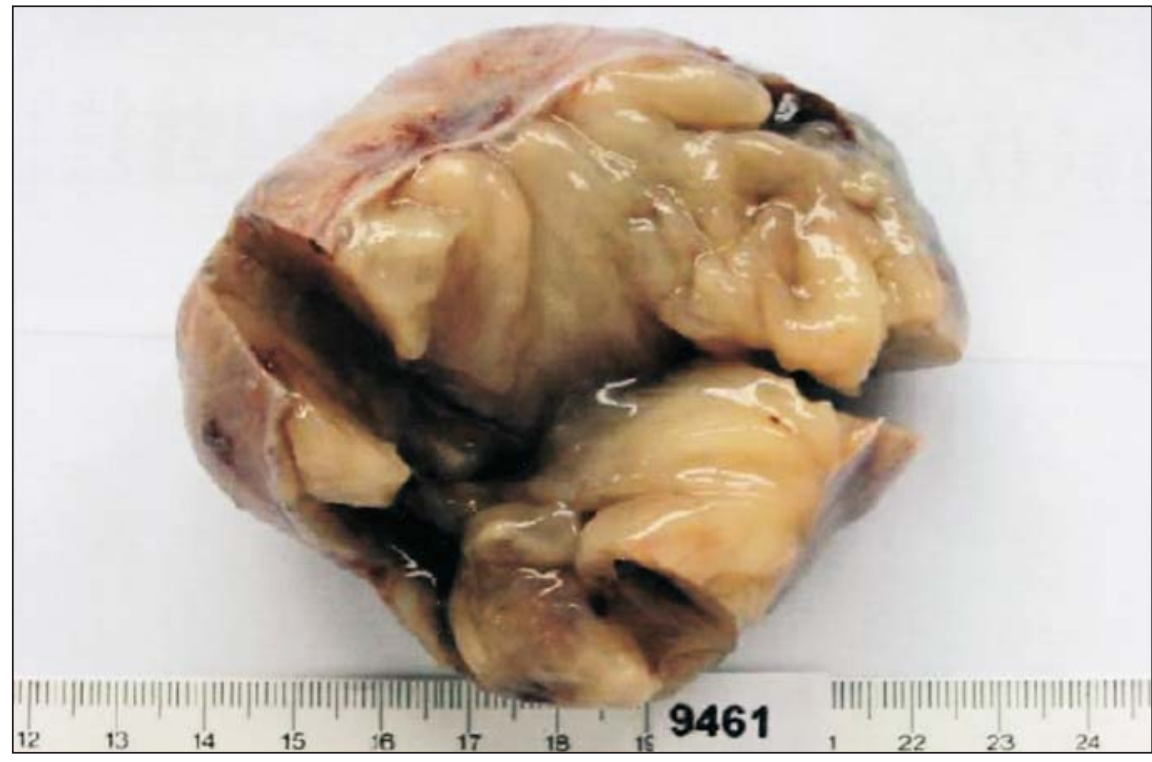

Figura 3. Exame macroscópico da lesão demonstrando massa heterogênea, com periferia esbranquiçada e firme e centro gelatinoso, medindo $9 \times 8 \mathrm{~cm}$.
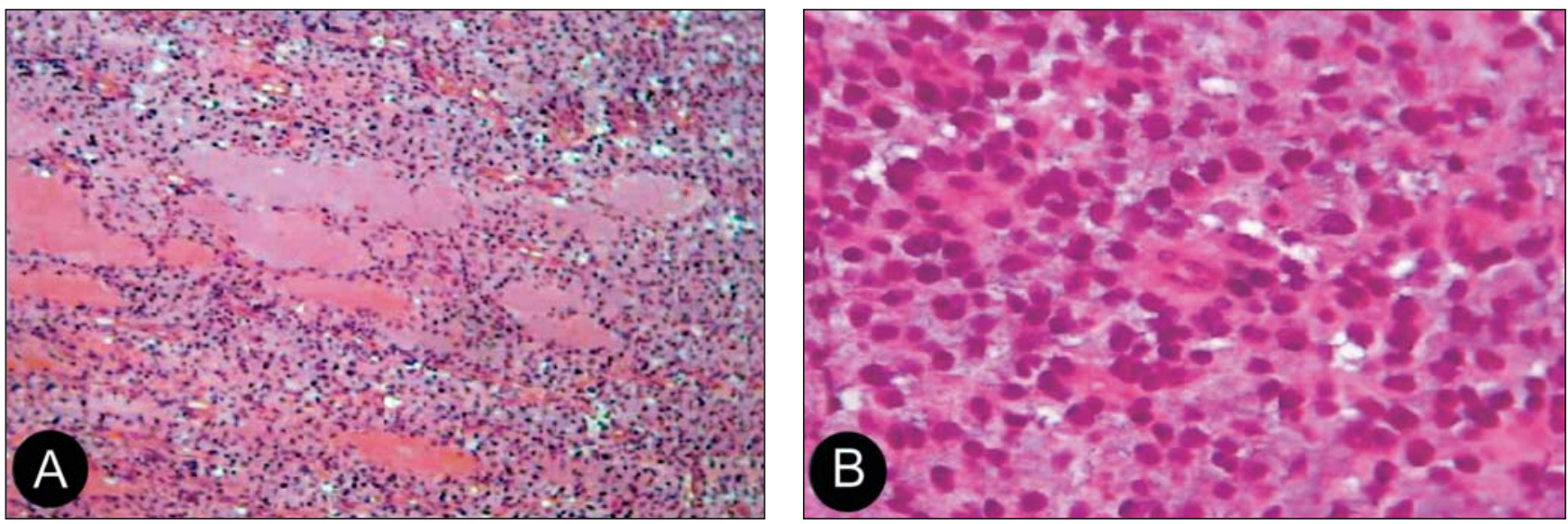

Figura 4. Fotomicrografia demonstrando estroma mixóide com proliferação de células fusiformes e ovais (HE, 100×); Em detalhe, células tumorais formando áreas em roseta (HE, $400 \times)$. 


\section{DISCUSSÃO}

Os sarcomas primários do tórax são raros, sendo que o diagnóstico somente pode ser considerado depois de excluídos os tumores primários do pulmão com aspecto sarcomatóide e as neoplasias pulmonares secundárias. Estes tumores são classificados de acordo com os achados histológicos e constituem um grupo amplo de neoplasias que acomete pulmões, mediastino, pleura e parede torácica. Os sarcomas intratorácicos primários mais comuns são os angiossarcomas, os leiomiossarcomas, os rabdomiossarcomas e os mesoteliomas (variante sarcomatóide). Sarcoma de Ewing, tumor primitivo neuroectodérmico, condrossarcoma, fibro-histiocitoma maligno, osteossarcoma, sarcoma sinovial e fibrossarcoma em geral ocorrem na parede torácica. Apesar dos sarcomas torácicos primários manifestarem-se comumente como massas grandes e heterogêneas, estas lesões têm aspecto radiológico variado, incluindo nódulos pulmonares solitários, tumores endobronquiais centrais e massas intraluminais nas artérias pulmonares. Os diferentes tipos histológicos de sarcoma em geral são indistinguíveis pelos métodos de imagem. Entretanto, diferenças na apresentação clínica e na localização do tumor, bem como achados como calcificações e envolvimento de arcos costais, podem ser úteis na tentativa de se estabelecer o diagnóstico diferencial acurado ${ }^{(3)}$. No presente caso, a tomografia computadorizada demonstrou massa arredondada de contornos bem definidos, com densidade entre 21 e 26 unidades Hounsfield, sugerindo aspecto cístico.

Os tumores mesenquimais representam $6 \%$ das massas mediastinais, sendo que a maioria são lipossarcomas. Estes tumores são classificados em quatro subtipos histológicos: bem diferenciado, mixóide, de células arredondadas, e pleomórfico. A variedade mixóide é formada por três componentes principais: proliferação lipoblástica, rede capilar delicada e matriz mucopolissacarídea. A matriz normalmente forma um depósito extracelular ${ }^{(4)}$, visível como massa heterogênea na tomografia computadorizada. Os valores de atenuação destas massas encontram-se entre os valores de gordura e partes moles. Quanto mais indiferenciada é a lesão, mais os valores de atenuação são semelhantes ao de tecidos sarcomatosos e de líquidos, provavelmente devido à grande matriz de ácido hialurônico. Na ressonância magnética, a presença de grande quantidade de matriz mixóide é a causa de tempo de relaxamento longo e homogêneo em $\mathrm{T} 1$ e $\mathrm{T} 2^{(5,6)}$. O padrão clássico é de tumores hipointensos em T1 e hiperintensos em T2. O tumor apresentado neste caso tinha uma pseudocápsula e estava localizado no mediastino posterior. Tais fatores sugerem o diagnóstico de cisto mediastinal, cujo principal diagnóstico diferencial a ser considerado é o de cisto broncogênico.

Os autores concluem que, apesar da apresentação cística na tomografia computadorizada ser rara nos casos de lipossarcoma de mediastino, esta entidade deve ser considerada entre os diagnósticos diferenciais de lesões císticas do mediastino posterior.

\section{REFERÊNCIAS}

1. Weiss SW, Goldblun JR. Enzinger and Weiss Soft tissue tumors. St. Louis: Mosby, 2001.

2. Eggerstedt JM. Lymphomas, endocrine, mesenchymal, and other rare tumors of the mediastinum eMedicine Journal [online]. January 2002; Available from: (C2001 eMedicine.com, Inc. Acessado em 15 de abril de 2003.

3. Gladish GW, Sabloff BM, Munden RF, Truong MT, Erasmus JJ, Chasen MH. Primary thoracic sarcomas. RadioGraphics 2002;22:621-37.

4. Jung JI, Kim H, Kang SW, Park SH. Radiological findings in myxoid liposarcoma of the anterior mediastinum. Br J Radiol 1998;71:975-6.

5. Arkun R, Memis A, Akalin T, Ustun EE, Sabah D, Kandiloglu G. Liposarcoma of soft tissue: MRI findings with pathologic correlation. Skeletal Radiol 1997;26:167-72.

6. Jelinek JS, Kransdorf MJ, Shmookler BM, Aboulafia AJ, Malawer MM. Liposarcoma of the extremities: MR and CT findings in the histologic subtypes. Radiology 1993;186:455-9. 